\title{
Sexuality during Pregnancy and Postpartum in suburbs of Dakar
}

\author{
Mamour Gueye, Mame Diarra Ndiaye Gueye, Moussa Diallo*, Mamadou Lamine Cisse, Omar Gassama, \\ Mouhamadou Mansour Niang, Abdoul Aziz Diouf and Jean Charles Moreau \\ Service de Gynécologie - Obstétrique, Centre Hospitalier National de Pikine, Sénégal
}

Submission: February 06, 2018; Published: February 15, 2018

"Corresponding author: Moussa Diallo, Service de Gynécologie - Obstétrique, Centre Hospitalier National de Pikine, sis Camp de Thiaroye, Dakar, Sénégal, Tel: 33 8530071; Fax: 338530069; EMail: moussadiallo25@hotmail.com

\begin{abstract}
Objectives: To determine the impact of the gestation period on sexual behaviour in women.

Patients and methods: This was a prospective study from 1 January to 31 May 2016 in the Dakar suburbs using a questionnaire between 3 and 6 months of delivery.

Results: The acceptance rate was $98.7 \%$. Nearly a quarter of women thought that having sex had a negative influence on pregnancy. However almost all women (96.7\%) had had sex during their pregnancy. More than half of women who gave birth by caesarean section (55.6\%) had not resumed sex, compared with $29.8 \%$ of women who had given birth by a low-birth route $(\mathrm{p}=0.009)$. More than half of the patients who resumed sex (58.3\%) had found them to be more satisfactory.
\end{abstract}

Conclusion: This study showed that pregnancy did not have a negative influence on sexuality. It is important to insist on the right information on sexuality during pregnancy and postpartum and to carry out more extensive studies on the subject in urban and rural areas.

Keywords: Sexuality; Pregnancy; Post-partum

\section{Introduction}

Until Masters and Johnson in 1966 [1], studies of sexuality during pregnancy were almost non-existent. These researchers were able, in vivo, to observe the sexual physiology of six pregnant women, and then substantiated their findings by interviewing more than one hundred couples. In the first trimester, they found a decrease in sexual activity for nulliparous women and little change in subsequent pregnancies. In the second quarter, an increase in eroticism and performance, regardless of the parity are noted and in the third quarter, there is a sharp drop in coital activity and a decline in sexual interest for the couple. Since then, various studies in the area of sexual and reproductive health have focused on understanding the relationship between the gestation period and sexual behavior. The majority of this research suggests that during pregnancy, both sexual desire and the frequency of sexual intercourse are declining considerably [2]. In addition, sexual activity during pregnancy can be strongly influenced by cultural, social or religious beliefs. The natural inconvenience of pregnancy (drowsiness, nausea, vomiting ...), the natural fear (but not justified) of hurting the fetus or complicating the course of pregnancy, are added hormonal changes that do not fail to act on mood and desire. All this makes that sexuality often takes second place to the detriment of the couple. In Africa, ignorance, old women's tales, and sometimes inappropriate medical advice, are such fears. Postpartum is also a difficult time for sexuality. In addition to the reasons already mentioned, there is often a depression, more or less important according to women, responsible for a decline in libido. The purpose of this study was to determine whether gestation period influences women's sexual behavior and to identify differences in sexual behavior in women before and during pregnancy and post-pregnancy. partum in suburban Dakar.

\section{Patients and Methods}

This is a prospective, analytical study conducted over a period of 4 months from January 1st to May 31st, 2016 at the Roi Baudouin Public Health Establishment located in the suburbs of Dakar. It was conducted as a survey conducted through interviews using a semi-structured questionnaire. The questionnaire was completed during an interview with a doctor in the final year of specialization in Gynecology-Obstetrics. The study population consisted of women seen during their postnatal consultations and ranging between 3 and 6 months of childbirth. We studied the socio-demographic data of patients, their antecedents, their opinions and practices on sexuality during pregnancy and postpartum and their possible suggestions 
regarding sexuality. Verbal consent was obtained from the women who agreed to participate in the survey. They were reassured about the confidential and anonymous nature of the work. Data was captured and analyzed using SPSS 17.0 software. For scale variables, we calculated averages and extremes. As for the qualitative variables, we had established percentages. Continuous variables were compared using the ANOVA test and those scaled using the Chi-square test or Fisher's exact test. The materiality threshold used was 0.05 .

\section{Results}

\section{Frequency}

The questionnaire was offered to 152 women, of whom 150 responded, an acceptance rate of $98.7 \%$.

\section{Socio-Demographic Characteristics}

The average age was 28.3 years with extremes of 16 and 43 years. They were almost all married (99.3\%); $22.7 \%$ lived in a polygamous regime. Half (48.7\%) were educated at the primary level, while $21.3 \%$ had completed secondary school and $2.7 \%$ had a university level. The age of the husband was known to 149 patients; he was 37.5 years old on average with extremes of 24 and 65 years old. Mean gestations were 3 (range 1 to 11), mean parity 2.8 (range 1 to 9), and mean number of live children 2.8 . The average length of the conjugal relationship was 7 years with extremes of 1 and 22 years.

\section{Perceptions, Attitudes and Practices of Women's Sexuality during Pregnancy}

The perceptions, attitudes and practices of women's sexuality during pregnancy are summarized. For 142 women (94.7\%), sexual intercourse was possible during pregnancy. For those who were of another opinion, the impossibility was motivated by the fear of hurting the fetus or being injured. Almost a quarter of women thought that sex had a negative influence on pregnancy. The main consequences cited were termination of pregnancy $(47.1 \%)$ and discomfort (32.3\%). However, almost all women (96.7\%) had sexual intercourse during their pregnancy. The main motivations for sex were marital duty, husband demand $(72.3 \%)$ or facilitation of delivery $(19.3 \%)$. The number of means of sexual intercourse per week was 1.1 with extremes of 1 sexual intercourse per month and 4 sexual intercourse per week.

\section{Perceptions, Attitudes and Practices of Postpartum Women's Sexuality}

Of the 150 women in our study, $76 \%$ had vaginal delivery versus $24 \%$ of cesarean delivery. More than 8 in 10 women $(87.3 \%)$ had opted for exclusive breastfeeding. At the time of the study, $59.3 \%$ of women had not had their menstruations return. Nearly half of the women $(n=63.42 \%)$ had received postpartum contraception. The method of choice was injectable contraceptives (39.7\%). The majority of women (38.1\%) started contraception 6 weeks after delivery. At the time of the survey, 96 women had resumed sexual activity, 33.3\% after 2 months.
More than half of women who delivered by caesarean section (55.6\%) had not resumed sexual intercourse compared to $29.8 \%$ of women who gave birth vaginally ( $p=0.009$ ). Episiotomy was not an influential factor in resumption of intercourse for women who gave birth vaginally. The frequency of sexual intercourse was one to two times per week in $73.9 \%$ of women. In most cases, resumption of intercourse was by mutual consent (60.4\%). $12.6 \%$ of women did not breastfeed. Of these, $31.6 \%$ had not resumed sexual intercourse against $36.6 \%$ of women who were breastfeeding ( $p=0.8)$. Sexual intercourse had increased in $54.7 \%$ of patients while they had decreased in only $7.4 \%$ of cases. More than half $(58.3 \%)$ of those who returned to sexual intercourse found them to be more satisfied; they were less satisfactory for $17.7 \%$ of women and identical for $24 \%$ of them. Whether or not they have resumed sex, only $13.3 \%$ (20 women) had expressed desire. The desire of these 20 women was motivated by personal pleasure.

\section{Discussion}

\section{Period chosen for the study and limits}

We chose to interview women in the postpartum period between 3 and 6 months. This time interval was chosen because it was close to delivery to remember the events of pregnancy. However, there may be a storage bias. Some women had difficulty answering some questions. Interviewing women during pregnancy may have been more appropriate.

\section{Accpetance rate}

Although sexuality is a sensitive topic and difficult to address, this study has benefited from a high response rate. In fact, out of 152 questionnaires proposed, we obtained the agreement of 150 women (98.7\%). This seems to show the interest of women in this subject. According to the literature, the subject of sexuality is relatively taboo [3]. The acceptance rate in our study is high compared to what is observed in other African countries. This is the case in the Massmoudi study where the non-response rate reached $56 \%$, reflecting the importance of reticence related to taboos that still hit the themes of sexuality [4]. This acceptance rate is comparable to other studies in Côte d'Ivoire and Burkina Faso $[5,6]$. In a European context, the non-response rate was only $5.7 \%[7]$.

\section{Sexuality during pregnancy}

The issue of sexuality rarely seems to be addressed during prenatal consultations. In the Bortellas's study [8], only $34 \%$ of the patients discussed it with their doctor and only $9 \%$ for Fok [9]. There are erroneous views of women about the possible consequences of the sexual act on pregnancy $[8,9]$, the most commonly cited being abortion and premature delivery $[10,11]$. Sayle's study [12] shows that the sexual act does not increase the risk of preterm birth but would facilitate the onset of term labor according to Tan [13]. Several authors [9,11,14] report a decrease in sexual activity during pregnancy and this as the pregnancy progresses. Here, as elsewhere, it is the male partner 
who initiates sexual act in the majority of cases $[10,11]$. However, it must be recognized with Von Sydow [15] that the male partner is not taken into account in most studies. As emphasized by many authors $[9,16]$ and reported by women in our study, there is a decrease in the pleasure of sexual intercourse and even desire during pregnancy. Despite the lack of pleasure generated by the sexual act, the majority of women in this study are engaged in it, in fact, to satisfy or retain the partner as pointed out by some authors $[10,11,14]$. Decreased satisfaction in the 3rd trimester for the majority of women could be correlated with the number of orgasms because it also sees its rate decrease in the 3rd quarter. We notice that lubrication remains unchanged for most women. This result is surprising because we noticed that most of the time in the 3rd trimester, there is a greater lubrication as well as larger vaginal discharge.

\section{Sexuality after childbirth}

After childbirth, about one-third of women plan to resume sexual activity on the 40 th day. The influence of the predominant Muslim religion in this group may explain this. It appears that breastfeeding women tend to delay resumption of sexual activity $[17,18]$. In this study, of the 96 women who returned to sex, only $30.2 \%$ resumed sex within 6 months. This percentage is quite low but can be explained by several parameters. In her study, Klein used the FSF index (Female Sexual Index Function) to compare couples' sexuality, by mode of delivery, 12 to 18 months after the birth of the child [19]. This index groups together: vaginal lubrication, awakening, desire, orgasm, pain and satisfaction. The higher the index, the greater the sexual difficulties encountered. Women who gave birth vaginally with an intact perineum had an index of 29.6 while women who had a caesarean had an index of 30.5. There were therefore no significant differences observed contrary to what we observed in our study. In our countries, to undergo a surgical operation is often not well lived because the general opinion thinks that it weakens the physical faculties of the person. The instrumental low pathway would result in twice as much risk of dyspareunia and five times more perineal pain than normal vaginal delivery [20]. During the postpartum, the body of the woman undergoes many transformations both gynecologically and generally. These "bodily harms of motherhood" can disrupt the sexuality of the couple [21].

The hormonal climate is not conducive to sexuality. In fact, a drop in estrogen and progesterone levels occurs at delivery. There is vaginal atrophy which results in less vaginal lubrication leading to vaginal dryness, which causes burns and pain during sexual intercourse [21]. In a country with limited resources, breastfeeding is part of children's livelihoods and therefore totally rooted in tradition. Vaginal dryness is more important during breastfeeding than when breastfeeding [21]. In addition, the flow of milk that can occur during sexual intercourse and nursing bras, not very glamorous, can dull desire in humans. In contrast, for Masters and Johnson, breastfeeding women show a sexual interest sooner after giving birth than women who do not breastfeed [22]. A majority of couples fear close pregnancies. This fear may explain the long delay before the resumption of sexual intercourse in our study. The child is ubiquitous, demanding, dependent on his parents and changes their pace of life. Thus, food, baths, exchange, housework, crying difficult to understand and rocking are repeated and focus the schedule of the couple but especially that of the woman around the newborn. Only the child counts. Acceptance of the parental role, the adaptation of the parents to this new rhythm of life and the communication play a primordial role in the resumption of the sexual intercourse.

\section{Conclusion}

In light of the results of this study and based on widespread misconceptions, we encourage physicians in charge of pregnant women to address the topic of sexuality during pregnancy and postpartum in order to provide adequate counseling. Larger studies seem essential to evaluate the real impact of pregnancy and postpartum on sexuality in urban and rural areas.

\section{References}

1. Pines M (1968) Human Sexual Response. A discussion of the work of Masters and Johnson. J Psychosom Res 12(1): 39-49.

2. Khamis MA, Mustafa MF, Mohamed SN, Toson MM (2007) Influence of gestational period on sexual behavior. J Egypt Public Health Assoc 82(1-2): 65-90.

3. Gaboriau S (2014) Modifications des pratiques sexuelles au cours de la grossesse. Etude rétrospective analytique de 108 patientes du Centre Hospitalo-Universitaire d'Angers du 22 octobre au 11 novembre 2013. Mémoire. Université d'Angers, Angers, France.

4. Masmoudi-Soussi J, Bellaaj-Lachtar F, Aloulou-Bouguecha J, Amami O, Halouani A, et al. (2006) Vie sexuelle des adolescents (enquête auprès de 352 étudiants tunisiens). Annales Médico-Psychologiques 164: 395401.

5. Kouakou JP, Doumbia Y, Djanhan LE, Ménin MM, Kouaho JC, et al. (2011) Réalité de l'impact de la grossesse sur la sexualité. Résultats d'une enquête auprès de 200 gestantes ivoiriennes. Gynecol Obstet Biol Reprod 40: 36-41.

6. Dao B, Some D-A, Ouattara S, Sioho N, Bambara M (2007) Sexualité au cours de la grossesse : une enquête auprès de femmes enceintes en milieu urbain africain. Sexologies 16: 138-143.

7. Legrand G (1993) Regard sur la sexualité d'un groupe d'adolescents. À propos d'une étude européenne. Thèse de Doctorat en Médecine. Lyon, France.

8. Bartellas E, Crane JM, Daley M, Bennett KA, Hutchens D (2000) Sexuality and sexual activity in pregnancy. BJOG 107(8): 964-968.

9. Fok WY, Chan LY, Yuen PM (2005) Sexual behavior and activity in Chinese pregnant women. Acta Obstet Gynecol Scand 84(10): 934-938.

10. Adinma JI (1995) Sexuality in Nigerian pregnant women: perceptions and practice. Aust N Z J Obstet Gynaecol 35: 290-293.

11. Naim M, Bhutto E (2000) Sexuality during pregnancy in Pakistani women. J Pak Med Assoc 50(1): 38-44.

12. Sayle AE, Savitz DA, Thorp Jr JM, Hertz-Picciotto I, Wilcox AJ (2001) Sexual activity during late pregnancy and risk of preterm delivery. Obstet Gynecol 97(2): 283-289. 
13. Tan PC, Andi A, Azmi N, Noraihan MN (2006) Effect of coitus at term on length of gestation, induction of labor, and mode of delivery. Obstet Gynecol 108(1): 134-140.

14. Orji EO, Ogunlola IO, Fasubaa OB (2002) Sexuality among pregnant women in South West Nigeria. J Obstet Gynaecol 22(2): 166-168.

15. Von Sydow K (1999) Sexuality during pregnancy and after childbirth. A metacontent analysis of 59 studies. J Psychosom Res 47(1): 27-49.

16. Adeyemi AB, Fatusi AO, Makinde ON, Omojuwa I, Asa S, et al. (2005) Changes in sexual practices and responses among ante-natal clinic attendees in a Nigerian teaching hospital. J Obstet Gynaecol 25(8): 796-802.

17. Rowland M, Foxcroft L, Hopman WM, Patel R (2005) Breastfeeding and sexuality immediately post partum. Can Fam Physician 51: 1366-1367.
18. Alder EM (1989) Sexual behaviour in pregnancy, after childbirth and during breast-feeding. Baillieres Clin Obstet Gynaecol 3(4): 805-821.

19. Klein K, Worda C, Leipold H, Gruber HP, Wenzl R (2009) Does the mode of delivery influence sexual function after childbirth? Journal of Women's Health 18(18): 1227-1231.

20. Brown SLJ (1998) Maternal Health after childbirth: Result af an Australian population based survey. British Journal of Obstetrics and Gynaecology 105-106.

21. Waynberg J (1994) Guide pratique de sexologie médicale. Editions Masson, pp. 51-56.

22. Masters William H, Johnson Virginia E (1968) Les reactions sexuelles. Robert Laffont, Paris, France.

\section{Your next submission with Juniper Publishers will reach you the below assets}

- Quality Editorial service

- Swift Peer Review

- Reprints availability

- E-prints Service

- Manuscript Podcast for convenient understanding

- Global attainment for your research

- Manuscript accessibility in different formats

( Pdf, E-pub, Full Text, Audio)

- Unceasing customer service

Track the below URL for one-step submission https://juniperpublishers.com/online-submission.php 